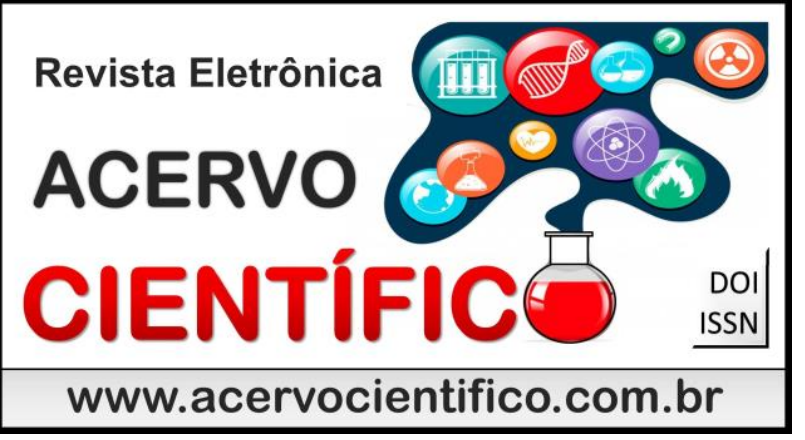

DOI: 10.25248/REAC.e331.2019

Recebido em: 8/2018

Aceito em: $8 / 2018$

Publicado em: 9/2018

\title{
Trajetórias e desafios da disciplina de sociologia
}

Trajectories and challenges of the sociology discipline

Trajetorias y desafíos de la disciplina de sociología

Cícera Poliana Alves de Sousa ${ }^{1 *}$, Deisy Moura Rodrigues Aguiar ${ }^{1}$, Edla Borges Marinho de Miranda1, Valdicléia Pereira da Silva ${ }^{1}$.

Resumo: O presente estudo tem como objetivo discutir a trajetória da disciplina de sociologia, tendo em vista que a sociologia e marcada pelas idas e vindas no currículo da educação básica. A sociologia proporciona ao individuo entender as relações sociais, os grupos sociais, ou seja, formar cidadãos mais conscientes dos acontecimentos que surge na sociedade. Para tanto se buscou percorrer a trajetória do ensino de sociologia com suas diversas inserções e retiradas do currículo, bem como as mudanças na lei e por fim apresentam os principais desafios, perspectivas atuais e futuras para a sociologia escolar brasileira. Para a realização desse estudo optou-se pela pesquisa bibliográfica e partimos de estudos de Amaury César Morais, Mário Bispo dos Santos dentre ouros autores. Com tudo, com o resultado do estudo concluise que mesmo diante dos desafios apresentados a disciplina de sociologia escolar brasileira encontra-se num momento, talvez como um divisor de águas e caberá a pressão junto às secretarias para o aumento das aulas semanais de sociologia, e profissionais formados exigirem a presença de um professor formado na área ministrando os conteúdos.

Palavras-Chave: Ensino de Sociologia, Ensino Médio, Educação.

Abstract: The present study aims to discuss the trajectory of the sociology discipline, considering that sociology is marked by comings and goings in the basic education curriculum. Sociology allows the individual to understand social relations, social groups, that is, to form citizens more aware of the events that arise in society. In order to do so, we sought to traverse the teaching of sociology with its various insertions and withdrawals from the curriculum, as well as changes in the law and finally present the main challenges, current and future perspectives for Brazilian school sociology. For the accomplishment of this study we opted for the bibliographical research and we start from studies of Amaury César Morais, Mário Bispo dos Santos among other authors. However, with the result of the study, it is concluded that even in the face of the challenges presented, the discipline of Brazilian school sociology finds itself in a moment, perhaps as a watershed and it will be the pressure with the secretaries for the increase of the weekly classes of sociology, and trained professionals require the presence of a trained teacher in the area teaching content.

Keywords: Teaching Sociology, Secondary Education, Education.

${ }^{1}$ Universidade Federal do Tocantins (UFT) *E-mail: polianaalves@mail.uft.edu.br 
Resumen: El presente estudio tiene como objetivo discutir la trayectoria de la disciplina de sociología, teniendo en vista que la sociología y marcada por las idas y venidas en el currículo de la educación básica. La sociología proporciona al individuo entender las relaciones sociales, los grupos sociales, o sea, formar ciudadanos más conscientes de los acontecimientos que surge en la sociedad. Para ello se buscó recorrer la trayectoria de la enseñanza de sociología con sus diversas inserciones y retiradas del currículo, así como los cambios en la ley y por fin presentan los principales desafíos, perspectivas actuales y futuras para la sociología escolar brasileña. Para la realización de este estudio se optó por la investigación bibliográfica y partimos de estudios de Amaury César Morales, Mário Obispo dos Santos de entre nuestros autores. Con todo, con el resultado del estudio se concluye que incluso ante los desafíos presentados la disciplina de sociología escolar brasileña se encuentra en un momento, tal vez como un divisor de aguas y cabrá la presión ante las secretarías para el aumento de las clases semanales de sociología, y profesionales formados exigen la presencia de un profesor formado en el área ministrando los contenidos.

Palabras clave: Enseñanza de Sociología, Enseñanza Media, Educación.

\section{INTRODUÇÃO}

A disciplina de sociologia é indispensável na formação do individuo, pois é através dela que podemos compreender o que acontece na sociedade. No espaço escolar a disciplina se efetiva através de um reconhecimento insuficiente, frágil e incerto, fato marcado paralelamente por disputa pela obrigatoriedade da mesma.

Desta forma, a pesquisa será mostrada um breve histórico do ensino de Sociologia no Brasil a partir de 1890 , ou seja, far-se-a um panorama do que vem a ser essa ciência no ensino médio uma vez que o ensino de sociologia permite estudar temas voltados ao cotidiano dos estudantes de uma maneira bem abrangente, o que possibilita também que os mesmos se reconheçam como seres sociais pertencentes à sociedade, uma sociedade considerada desigual por sua condição social, política e cultural.

O ensino da disciplina de sociologia na estrutura curricular brasileira esteve sempre envolto em afirmações e desconfiança, pois muitas foram às inserções, como também foram diversas retiradas do currículo oficial. Ora a contextualização histórica, ora a situação política ou mesmo outros fatores, o fato é que a sociologia como disciplina escolar demorou quase de um século para de fato ser ofertada na grade curricular. Desta forma, entender o ensino da sociologia na perspectiva do currículo oficial atualmente requer um exercício de analise histórica da mesma.

Portanto, para a melhor compreensão do leitor, o presente texto está organizado em duas partes que sejam: 1) História da sociologia como disciplina no Brasil; e, 2) Os desafios e perspectivas atuais da sociologia escolar no Brasil.

De modo geral, o presente estudo apresentará algumas questões relevantes ao processo de ensino da disciplina de sociologia no ensino médio. Possibilitará a reflexão sobre a prática e a realidade escolar tendo em vista o histórico da referida disciplina e a necessidade constante de se reafirmar, seja por meio legal, lutando pela inserção no currículo, seja por meio real, em busca da afirmação e valorização no cotidiano escolar.

\section{HISTÓRIAS DA SOCIOLOGIA COMO DISCIPLINA NO BRASIL}

A história da "Sociologia como disciplina no Brasil" é um tema um pouco complexo porque o percurso é marcado pelas idas e vindas da disciplina nos currículos escolares da educação básica no brasil. Para se ter uma breve noção do que ocorreu nesse período sobre a sociologia Moraes (2003, p. 08) salienta que: 
1890-1897 - Com a Reforma de Benjamim Constant a disciplina é incluída como obrigatória nos cursos preparatórios, (6 $6^{\underline{a}}$ ao $7^{\underline{a}}$ anos do secundário), obrigatoriedade que não resultou em inserção efetiva.

1897-1925 - Com a Reforma Rocha Vaz, a disciplina torna-se obrigatória nos 6o e 7aa anos e seus conteúdos são exigidos nas provas de vestibulares para o ensino superior.

1925-1942 - Vigência da Reforma Capanema, por meio da qual a sociologia foi excluída do currículo, não aparecendo como obrigatória nem no curso clássico nem no científico.

1961 - Com a Lei 4.024/61, a primeira Lei de Diretrizes e Bases da Educação Nacional (LDB) a disciplina passa a figurar como componente optativo no curso colegial.

1961-1971 - A disciplina embora optativa apresente dificuldade para ser incluída, por conta do preconceito reinante em que se confundia sociologia com socialismo.

1971-1986 - Particularmente no estado de São Paulo a resolução Secretária da Educação SE no236/83 possibilitou a inclusão da disciplina na grade curricular do ensino secundário. Em 1985, cerca de $25 \%$ das escolas tinham excluído a disciplina de sociologia; em 1986 a Secretaria de Educação do Estado de São Paulo realizou concurso público para o provimento de cargo de professor de sociologia.

1992-1994- Em 1992 A Coordenadoria de Estudos e Normas Pedagógicas (Cenp) apresentou outra "Proposta para o Currículo do Ensino de Sociologia-2º grau, nos anos de 1993 a 1994 houve novos concursos e posses de aprovados.

1994-1996 - Foi promulgada a nova LDB Lei (9394/96), cujo teor no artigo 36, parágrafo 1ํinciso III, estabelece que no final do ensino médio o educando demonstre: domínio de sociologia e (filosofia) necessária ao exercício da cidadania.

A partir dessa contribuição de Moraes (2003), constata-se que o ensino médio passou por várias reformas ao longo dos anos, e nada contribui para a valorização da sociologia, uma vez que a disciplina entrava e saia do currículo. Contudo, somente no final da dos anos 90 , que a sociologia se configurou como uma disciplina que conduzia o aluno aos conhecimentos de cidadania. Dando continuidades a essas considerações Santas (2002, p. 66) aponta que:

1997- A sociologia torna-se disciplina obrigatória do vestibular da Universidade Federal de Uberlândia.

1998- Aprovação do parecer no 15 de 1ํ de junho com as Diretrizes Curriculares Nacionais para o Ensino Médio (DCNEM), nas quais os conhecimentos de sociologia são incluídos nas áreas de Ciências Humanas e suas tecnologias.

1999- Ministério da Educação lança os Parâmetros Curriculares para o Ensino Médio (PCNEM) que trazem as competências relativas aos conhecimentos de sociologia, antropologia e ciência política.

2000- No novo currículo das escolas pública do Distrito Federal, a sociologia aparece como disciplina obrigatória nas três séries do ensino médio, com carga semanal de 2 horas- aula.

Pode-se observar que a disciplina passa a ser obrigatória na primeira década do séc. XXI. Porém, logo depois com a implantação de novas reforma deixa de fazer parte dos currículos de ensino médio. Contudo, essa desvalorização que se aplica a disciplina de sociologia, e consequência da própria educação como aponta Moraes (2003) "a educação há muito tempo vem passando por um processo de desvalorização" (p.10).

Segundo Florêncio (2009), a sociologia surgiu em meio à crise econômica da Revolução Industrial esta representada pela Revolução Francesa, e assim em meios a essas reviravoltas, e diante dos novos modos de vida, surge uma nova sociedade, a qual denominou capitalismo.

Prosseguindo com a exposição, Florêncio (2011) a primeira reforma foi a reforma de Benjamin Constant, que objetivava concretizar uma estrutura educacional mais ampla e assim colocando a sociologia como uma disciplina obrigatória No entanto com afastamento de Benjamim Constant a sociologia passa a não fazer mas parte das grades curriculares o que coloca a sociologia como uma disciplina frágil. Logo após, em 
1925, surge à reforma rocha Vaz, que inclui novamente os conteúdos de sociologia nas grades curriculares. É importante destacar também, que logo depois veio a Reforma de Gustavo Capanema, no ano de 1942.

Essa lei orgânica do ensino secundário passou a ofertar o ginásio em quatro anos do quinto ao oitavo ano e, em seqüências mais três anos de escolarização, podendo, nesta segunda fase, o aluno escolher entre o clássico, que era voltado para o conhecimento de filosofia e letras, e o científico, que era marcado pelo estudo das ciências e matemática (Moraes, 2011). A sociologia não tinha ganhado legitimidade para compor o grupo das ciências escolares curriculares, pois não estava presente nos currículos clássicos e científicos.

Os debates referentes à importância do ensino de sociologia, na escola secundária brasileira ocorreram por volta de 1954, no primeiro Congresso Brasileiro de Sociologia, onde Florestan Fernandes considera favoráveis à sua introdução nos currículos, apontando sua relevância no processo formativo dos jovens. Mas precisamente em 1961, no mandato do Presidente João Goulart foi elaborado a primeira Lei de Diretrizes e Bases da Educação, a LDB.

Contudo, mesmo com tantas mudanças nos currículos não modificaram muita a estrutura antiga do ensino, permanecendo a mesma divisão do nível médio em ginasial e colegial. Quanto à sociologia, nada foi mencionado sobre a sua reinserção nos quadros do ensino secundário. No entanto, com a implantação da LDB no 4.024/61, que os estados brasileiros pode ganhar certa autonomia para a indicação de disciplinas optativas no currículo do ensino médio, e assim, cabendo ao Conselho Federal apenas a indicação das disciplinas obrigatórias.

No entanto, a maioria dos estados não conseguiria, arcar com as despesas de contratação de profissionais para lecionarem as disciplinas optativas, mantendo-se assim apenas as de caráter obrigatório, de modo que a inclusão da sociologia se tornou mais uma possibilidade do que uma realidade (SANTOS 2002).

Em conseguência do regime militar, causada pelo fracasso econômico e pelos problemas sociais que enfrentava o Brasil, tanto a filosofia como a sociologia ocupou pouco espaço de tempo nos currículos educacionais, Sendo assim, a disciplina de sociologia foi substituídas pelas disciplinas de educação moral e cívica e OSPB. Cabe lembrar também, que somente com o fim do regime militar que as duas disciplinas voltam aos currículos escolares de forma mais restrita (Vargas, 2010). Em 1971 com a Reforma Jarbas Passarinho, o ensino médio se pautava na profissionalização, ou seja, qualificando os indivíduos para um crescente processo de industrialização que cada vez mais exigia técnicas de diversos meios de produção.

Fazendo uma avaliação do Ensino Médio como etapa de formação, Silva (2009, p. 03) defende que:

Definir uma identidade para a etapa do Ensino Médio tem sido difícil no Brasil, em função do descompromisso para com os trabalhadores por parte das elites governantes (...). Enquanto esta etapa era privilégio de uma minoria de jovens até os anos de 1970, havia algumas definições mais visíveis, os currículos eram mais densos e visavam ilustrados e humanistas, no sentido de preparar as elites profissionais e políticas do país. Em 1980, a política educacional começa a alterar sua ênfase, assim formar o cidadão, o indivíduo flexível, adaptado ao mundo globalizado, torna-se o objetivo da Educação Básica.

Com essa contribuição de Silva, o ensino médio é uma etapa de ensino que prepara o jovem para a vida e para a construção de sua autonomia. E nesse processo é importante o papel da sociologia e de outros conteúdos capazes de formar integralmente o cidadão, pois, além de preparar para o mercado de trabalho, a sociologia busca preparar o aluno para analisar a vida em sociedade.

Somente com a redemocratização do país em 1982 que o currículo do $2^{\circ}$ grau foi reformulado e dessa forma cabendo a escola incluir ou não os conteúdos de sociologia. Em 1983, foi feito um protesto em São Paulo pela volta da sociologia nos $2^{\circ}$ graus, esse movimento envolveu vários intelectuais, estudantes e outros membros da sociedade. Sendo assim, devido a esse movimento a disciplina de sociologia foi ganhando espaço e com isso foram oferecidos concursos para os professores de sociologia. 
Considerando as reflexões de Moraes (2011) e Santos (2002), presentes no início deste trabalho, entre os anos de 1982 e 1983, com as reivindicações dos professores, e membros da sociedade em prol da volta do ensino de sociologia no Estado de São Paulo a disciplina volta para o currículo com mais força e com professores formados.

Segundo o Ministério da Educação (2007), como o texto da LDB de 1996 a educação brasileira fica estruturada em Educação básica e educação superior; com as modalidades de educação de jovens e adultos e a educação especial, e uma modalidade complementar, a educação profissional. Com a promulgação dessa lei, de no 9394/96, no seu artigo 36, sobre o currículo do Ensino Médio, inciso III, está preconizado o domínio dos conhecimentos de Filosofia e de Sociologia necessários ao exercício da cidadania.

Neste ponto, pode-se dizer que a Sociologia retorna para o currículo, porém, ainda não como disciplina obrigatória, fato este que só vai acontecer nas Diretrizes Curriculares Nacionais para o Ensino Médio (DCNEM), aprovada em $1^{\circ}$ de junho de 1998. Com a mudança no antigo núcleo 8, comum para o Ensino Médio, a organização não seria mais por disciplina e sim por áreas de conhecimento, a saber: Linguagens, Códigos e suas Tecnologias; Ciências da Natureza, Matemática e suas Tecnologias e Ciências Humanas e suas Tecnologias. De acordo com Santos (2002) as disciplinas de Filosofia e Sociologia estariam presentes nas áreas de Ciências Humanas e suas Tecnologias. Somente com a aprovação da lei no 11.684, de 2 de junho de 2008, fato não muito distante, que a Sociologia e a Filosofia tornam-se disciplinas obrigatórias em todas as séries do Ensino Médio.

No patamar educacional, a sociologia surge como disciplina entre cursos superiores e depois de um curto caminho é instituída como Cátedra na Universidade de Sorbonne (França) no ano de 1902. Na contextualização histórica da sociologia, Lakatos (2006) apresenta outros expoentes na consolidação da mesma como ramo do saber, segunda a autora destacam-se também:

Montesquieu (1689-1775) que na obra o espírito das leis analisou o papel da lei e dos poderes político na sociedade; David Hume (1711-1776) [...] escreveu a obra o tratado sobre a natureza humana; Adam Smith (1723-1790) que relacionou suas analises econômicas com o conjunto da sociedade; [...] Jean Jacques Rousseau (1712-1778) de decisiva influência na revolução democrática e, conseqüentemente, historia das instituições; sua primordial importância consiste na apresentação de uma teoria para fundamentar a legitimidade do poder. $(p, 44)$

Observamos que dos muitos autores que contribuíram para o desenvolvimento da sociologia, três tem destaque especial e gozam do prestigio de serem considerados fundadores ou "pais" da sociologia, pois foi a partir dos estudos destes autores que a sociologia ganhou caráter e cientificidade além de ser transformada em disciplina acadêmica, são eles: David Émile Durkheim (1858-1917), Karl Heinrich Marx (1818-1864) e Maximilian Carl Emil Weber (Max Weber) (1864-1920). Destes considerados fundadores Durkheim foi quem recebeu o titulo de sociólogo, após a criação da primeira cátedra de sociologia em 1910, consolidando assim o status acadêmico da disciplina.

Mesmo, instituída oficialmente por lei como disciplina curricular secundário, a sociologia enfrentou diversos problemas, pois a mesma estava envolta num projeto de domínio social, nesse aspecto, de acordo com Santos (2002) haveria um sentimento compartilhado pela elite, de que os problemas sociais deveriam ser superados, afinal o novo Brasil agora republicano ainda convivia com problemas herdados do império. Apesar disso, a elite detentora do poder não se encontrava preparada para solucionar tais problemas. Diante dessa circunstancia o pensamento elitista esperava da sociologia um caráter social pratico, formando lideranças que fossem capazes de atuar na resolução desses conflitos.

Como é possível observar, a sociologia ainda buscava encontrar seu espaço mesmo na euforia da nova República. Sendo necessária a luta engajada de professores e intelectuais para que a mesma fosse reconhecida como disciplina escolar. Complementarmente a partir dessa luta as disciplinas de sociologia e filosofias foram sendo incorporadas nos Estados brasileiros paulatinamente como disciplinas obrigatórias. 


\section{OS DESAFIOS E PERSPECTIVAS ATUAIS DA SOCIOLOGIA ESCOLAR NO BRASIL.}

Atualmente a sociologia como disciplina escolar é considerada pela Base Nacional Comum Curricular como obrigatória, no entanto, faz-se necessária algumas explicações. Para se chegar a este ponto como foi descrito anteriormente muitas lutas aconteceram, muitos foram os avanços como também foram os retrocessos. Seguindo essa ótica abordaremos as perspectivas a partir do ultimo parágrafo do item anterior.

Sabe-se que havia uma movimentação continua e constante para que as disciplinas de sociologia e filosofia entrassem de vez na grade curricular oficial do país, os Estados já haviam feito, mas as mesmas eram optativas, era necessária uma lei federal instituindo as mesmas como obrigatórias.

Se contextualizarmos o período histórico aqui descrito observaremos uma profunda mudança no comportamento da sociedade brasileira, sensação de liberdade após 25 anos de ditadura aflorava a pele, a sociedade em ebulição exigia participação direta na escolhas dos governantes, queria fazer parte da vida política, nessa fase os movimentos sindicais arregimentavam milhares de pessoas as ruas na defesa de seus direitos, a política ganhara ares populares e era discutida desde a academia até o "botequim" tornando-se necessária novas explicações. Daí começa a surgir explicações para esses fenômenos nos meios de comunicação os sociólogos, e alguns se destacam como é o caso de Darci Ribeiro e outros.

A promulgação da Constituição Federal de 1988 foi o ápice das conquistas, no entanto ela deixou para leis complementares assuntos relativamente importantes para o país. Na educação, por exemplo, ficou estabelecido que se elaborasse uma nova LDB.

Os anos seguintes o país passara por uma profunda crise econômica e política, culminando com o impeachment de Fernando Collor de Melo, sendo substituído por seu vice o mineiro Itamar Franco que teve como principal legado a criação do plano Real que tiraria do anonimato o então ministro da fazenda Fernando Henrique Cardoso e o elegeria mandatário maior da nação. No tocante a educação, nos dois mandatos exercidos por FHC foram importantes, nesse período o Brasil aprovou uma de suas melhores leis. Apesar de alguns vetos presidenciais, foi em 1996 que a Lei de Diretrizes e Bases da Educação brasileira (LDB) foi aprovada. No tangente a Sociologia a lei é muito vaga e apenas em seu artigo 36, parágrafo primeiro e inciso III, afirma "domínio dos conhecimentos de Filosofia e de Sociologia necessários ao exercício da cidadania", sem definir critérios ou formas de implantação. Mas esse tema será debatido mais adiante.

Podemos afirmar que governo de FHC, contrariou o que se esperava. Uma vez que devido a sua formação acadêmica em Sociologia, o mesmo poderia contribuir para a consolidação da sociologia escolar, o que não se viu, pois esse período acabou sendo muito ruim para a sociologia escolar. O que aconteceu é que mesmo sendo ele um famoso sociólogo, conduziu através de seu ministro da educação, Paulo Renato de Souza, a reforma do ensino médio. Reforma que foi confirmada pelo parecer 03/98 do CNE (Conselho Nacional da Educação), este parecer não contempla a sociologia e a filosofia como disciplinas obrigatórias. Sobre o tema, Santos (2002) afirma:

De acordo com as DCNEM, [...] os estudos de filosofia e sociologia estarão presentes na área de Ciências Humanas e suas tecnologias, para que se cumpra a determinação expressa no art. 36 da LDB. Todavia, domínio dos conhecimentos de Filosofia e de Sociologia necessários ao exercício da cidadania. (p. 56)

Mais uma vez observamos a sociologia, tal qual a filosofia não sendo contempladas, mas essa realidade estaria prestes a mudar pois com a saída de FHC do governo assume o presidente Luiz Inácio LULA da Silva o "LULA" com iniciativas populares e projetos que buscavam valorizar a dignidade humana promoveu em poucos anos uma profunda revolução na forma de pensar e fazer política no país sendo este lembrado pelo povo até os dias atuais. Na educação coube a LULA através de seu ministro Fernando Haddad que a Sociologia finalmente passa a ser componente obrigatório no currículo escolar na forma de disciplina, como mostra a Lei $n^{\circ} 11.684$ de dois de junho de 2008, em sua alínea IV altera o artigo 36 da LDB, " IV- serão inseridas a filosofia e a sociologia como disciplinas obrigatórias em todas as series do ensino médio" deveria se ter pelo menos uma aula por semana em cada turma de ensino médio. 
LULA consegue eleger sua sucessora Dilma Roussef (em 2010) que continua seu legado, ao ponto de se reeleger em 2014. No entanto, vê seu segundo mandato diluir-se em meios as dificuldades financeiras e acusações diversas que nunca foram provadas, e finalmente agonizando sucumbe a um golpe parlamentar em 31 de agosto de 2016.

O novo governo chefiado por seu vice Michel Temer inicia uma agenda de reformas e propõe a Medida Provisória (MP) 746/16 que tratava da reforma do ensino médio, ela visa alterar a LDB transformando disciplinas que antes eram tidas como obrigatórias em conteúdo dentro de temas.

A Medida Provisória esta que se tornaria a Lei 13.415/17 e fora apresentada como peça propagandista do governo nos meios de comunicação em massa mostrando um novo ensino médio inovador, mas ao observarmos bem, nota-se que o mesmo nada mais é do que mais um retrocesso na educação brasileira, pois o modelo profissionalizante proposto é uma reedição do modelo de educação profissional vigente no governo militar que declinou ainda no ano de $1982 \mathrm{com}$ o fim do Regime. Esse modelo apresenta algumas incongruências e pode incorrer no mesmo erro cometido pelos militares, de não preparar o egresso do ensino básico nem para o mercado de trabalho nem para a vida acadêmica. Além de ser uma notória tentativa de afastar os jovens das universidades, pois uma vez no mercado de trabalho, subentende-se que como na visão tecnocrata da educação vista durante o governo militar, este individuo não tentará o ensino superior.

Inicialmente a proposta da lei não contemplaria o ensino de artes, sociologia, filosofia e educação física, mas, após muita luta o governo recuou e reconheceu tais disciplinas como obrigatórias. Cabe-nos apresentar o caso da sociologia.

Não bastam as tantas inserções e retiradas da grade curricular, estava a sociologia mais uma vez a beira de ser excluída do currículo oficial, mas como já foi dito aqui a ação organizada e do enfrentamento a mesma permaneceu na BNCC.

Por ultimo vemos ataques de todos os lados, mais recentemente mais precisamente no dia 16 de abril de 2018, a folha de são Paulo utilizando-se de pesquisa realizada pelo IPEA para culpa a filosofia e a sociologia pelo baixo desempenho em matemática, apresenta-se a seguir matéria publicada pelo referido jornal:

Em matéria assinada pela jornalista Érica Fraga, a folha mostra que a inclusão de filosofia e sociologia como disciplinas obrigatórias no ensino médio prejudicou o aprendizado de matemática dos jovens brasileiros, principalmente os de baixa renda. Para os pesquisadores o declínio foi verificado na aplicação das provas do exame nacional do ensino médio (ENEM) de 2012, foram analisados estudantes concluintes em 2009 que foram afetados pela lei que tornou obrigatórias as disciplinas em comparação com alunos que concluíram três anos antes e a tendência observada foi a de que em português e ciências humanas as notas até melhoraram em outro cenário não houve alteração, mas destaca-se o fato de que em todos os cenários as notas de matemática caíram. A hipótese dos pesquisadores é a de que com a limitação da carga horária do ensino médio, a inserção de qualquer disciplina reflete na redução no tempo dedicado as demais.

Observa-se a tendenciosa forma de apresentar a pesquisa, uma vez que não se discute a qualidade do ensino, a queda no investimento em educação se quer levam em consideração que a culpa pode está em outro fator, estabelece a critica sem se preocupar em apresentar solução, no entanto, há em curso uma reforma que pretende ampliar a carga horária para integralização do ensino médio, nesse aspecto caberá futuramente a comprovação ou negação dessa hipótese, portanto, ainda é prematuro estabelecer uma relação direta do baixo desempenho dos alunos em matemática com a implantação obrigatória da filosofia e sociologia.

Não bastam as tantas inserções e retiradas da grade curricular, estava a sociologia mais uma vez a beira de ser excluída do currículo oficial, mas como já foi dito aqui a ação organizada e do enfrentamento a mesma permaneceu na BNCC.

Por ultimo vemos ataques de todos os lados, mais recentemente mais precisamente no dia 16 de abril de 
2018, a folha de são Paulo utilizando-se de pesquisa realizada pelo IPEA para culpa a filosofia e a sociologia pelo baixo desempenho em matemática, apresenta-se a seguir matéria publicada pelo referido jornal:

Em matéria assinada pela jornalista Érica Fraga, a folha mostra que a inclusão de filosofia e sociologia como disciplinas obrigatórias no ensino médio prejudicou o aprendizado de matemática dos jovens brasileiros, principalmente os de baixa renda. Para os pesquisadores o declínio foi verificado na aplicação das provas do exame nacional do ensino médio (ENEM) de 2012, foram analisados estudantes concluintes em 2009 que foram afetados pela lei que tornou obrigatórias as disciplinas em comparação com alunos que concluíram três anos antes e a tendência observada foi a de que em português e ciências humanas as notas até melhoraram em outro cenário não houve alteração, mas destaca-se o fato de que em todos os cenários as notas de matemática caíram.

A hipótese dos pesquisadores é a de que com a limitação da carga horária do ensino médio, a inserção de qualquer disciplina reflete na redução no tempo dedicado as demais.

Observa-se a tendenciosa forma de apresentar a pesquisa, uma vez que não se discute a qualidade do ensino, a queda no investimento em educação se quer levam em consideração que a culpa pode está em outro fator, estabelece a critica sem se preocupar em apresentar solução, no entanto, há em curso uma reforma que pretende ampliar a carga horária para integralização do ensino médio, nesse aspecto caberá futuramente a comprovação ou negação dessa hipótese, portanto, ainda é prematuro estabelecer uma relação direta do baixo desempenho dos alunos em matemática com a implantação obrigatória da filosofia e sociologia.

\section{CONSIDERAÇÕES FINAIS}

Chegamos à conclusão que a sociologia mesmo estando presente nas discussões sobre educação desde 1890 pode ser considerada recente na matriz curricular, pois, suas inserções e retiradas do currículo fez com que a mesma não conseguisse a maturidade necessária para consolidar-se como disciplina ministrada nas escolas públicas.

Como desafios observarmos que a descontinuidade na oferta da disciplina provocou um rompimento no fluxo continuo que diminuiu o interesse de acadêmicos na formação de professores nessa área em relação a outras graduações, esse fato provocaria uma carência de profissionais para atuarem na Sociologia. Dessa forma motivou algumas das justificativas daqueles que não queriam ver a sociologia no currículo oficial do ensino médio, pois entendiam que por falta de profissionais o melhor era não oferecer a disciplina. $O$ efeito pode ser observado na carência de profissionais da área ministrando a disciplina.

Outro desafio é que para se entender a Sociologia no contexto histórico e político, precisa- se observá-la a partir de um olhar político ideológico, tornando cada período um laboratório de analise onde nota-se que a sociologia, dependendo de qual seja o viés ideológico do governo é inserida ou desprestigiada. Desta forma, se o governo tem um viés ditatorial ou neoliberal logo é retirada a sua obrigatoriedade. No governo militar, por exemplo, a sociologia se quer foi debatida nos seus primeiros anos, vindo a ser implantada de fato por iniciativa dos Estados apenas após o enfraquecimento e eminente queda daquele regime, o viés tecnológico profissional do ensino médio no governo militar mostra claramente uma sobreposição das disciplinas técnicas e de linguagens em relação à de humanas.

Vimos ainda que após o governo militar, o grande desafio da sociologia consistia em garantir a sua implantação e obrigatoriedade no currículo, mas como vimos isso não foi tão fácil assim, o período entre a Lei 9394/96 e a obrigatoriedade foi de 10 anos e ainda assim não foi de fato instituída como deveria, deixando-a na maioria das vezes a mercê de professores de outras áreas impedindo assim a fluidez e aprendizagem do conteúdo prejudicando bastante a disciplina e os alunos. 
Nesse aspecto Nunes e Lopes (2012) afirmam que:

[...] Temos em vista que esta disciplina em sua maioria é ministrada por professores que não são formados na área, sendo o seu espaço no currículo destinado apenas uma aula por semana, o que corresponde $20 \mathrm{~h}$ na carga horária do professor, bem como, o grande risco que ocorre de ser mal trabalhada ou compreendida pelos alunos do Ensino Médio, pois como promotora do conhecimento científico social o professor deverá trabalhar conforme previsto nos Parâmetros Curriculares Nacionais para o Ensino Médio - PCNEM (BRASIL, 2004) a articulação das Ciências Sociais que corresponde a temas, conceitos, conteúdos, ligados a Sociologia, a Política e a Antropologia, o que requer que o professor seja formado nesta área. (P.3)

Agora apenas dez anos depois de se tornar obrigatória, vê-se na responsabilidade de se consolidar e expandir. Mas outro desafio salta aos olhos, como se consolidar tendo que enfrentar as investidas governamentais na tentativa de suprimi-la mais uma vez do currículo?

Mas, mesmo diante dos desafios apresentados, a sociologia escolar brasileira encontra-se num momento, talvez como um divisor de águas com a reforma do ensino médio, com o aumento da carga horária empreendido pelo governo, e com a liberdade que cada sistema de ensino poderá ter para adequar sua grade curricular, caberá a pressão junto às secretarias para o aumento das aulas semanais de sociologia, e caberá aos profissionais formados exigir a presença de um professor formado na área ministrando os conteúdos.

Outra perspectiva observada é o engajamento e a luta de professores, intelectuais, artistas, alunos e da sociedade em geral para que disciplinas como Sociologia, Artes e filosofia permaneçam na grade curricular propiciando assim uma formação ampla de caráter critico ao cidadão.

\section{REFERÊNCIAS}

1. BRASIL. Lei de Diretrizes e Bases da Educação Nacional. Lei número 9394, 20 de dezembro de 1996. http://www.planalto.gov.br/ccivil 03/LEIS/L9394.htm, consultado em 15 de abril de 2018, às 11h23min.

2. Lei 11.684 de $2 \quad$ de junho de 2008.

http://www.planalto.gov.br/ccivil 03/ Ato2007-2010/2008/Lei/L11684.htm consultado em 02 de abril de 2018.

3. CZERNISZ, Eliane Cleide Silva. GARCIA, Sandra Regina Oliveira. A minimização da formação dos jovens brasileiros: alterações do ensino médio a partir da lei 13415/2017. Educação, Santa Maria, v. 42, n. 3; p. 569-584, set./dez. 2017.

4. FLORÊNCIO, Maria Amélia de Lemos. A Sociologia no Ensino Médio. O percurso histórico no Brasil e em Alagoas. 2009.

5. FOLHA DE SÃO PAULO - https://www1.folha.uol.com.br/educacao/2018/04/filosofia-e-sociologia-obrigatorias-derrubam-notas-emmatematica.shtml visto em18/04/2018

6. LAKATOS, Eva Maria. Sociologia geral / Eva Maria Lakatos, Marina de Andrade Marconi - 7. Ed. Ver. E ampl. - 7. Reimpr. - São Paulo: Atlas, 2006.

7. MORAES, César Amaury. Desafios para a implementação do Ensino de Sociologia na escola media brasileira. Cadernos do NUPPs. Ano 2. Setembro de 2010. São Paulo - SP.

8. NUNES, Klívia de Cássia Silva. DOMINGUES-LOPES. Rita de Cássia. O trabalho docente na Sociologia: histórico e atualidades. XV ENCONTRO DE CIÊNCIAS SOCIAIS DO NORTE E NORDESTE e PRÉ- ALAS BRASIL - UFPI. TERESINA- PI. 04 a 07 de setembro de 2012

9. QUINTANEIRO, Tânia. Um toque de clássicos: Marx, Durkheim e Weber / Tânia Quintaneiro, Maria Ligia de Oliveira Barbosa, Márcia Gardênia de Oliveira. -2ª Ed.rev. amp. -Belo Horizonte: Editora UFMG, 2002. 